CUBO A Mathematical Journal

Vol.19, $N^{\underline{O}} 01$, (17-38). March 2017

\title{
Hilfer and Hadamard Functional Random Fractional Differential Inclusions
}

\author{
SaÏD Abbas ${ }^{1}$, Mouffak Benchohra ${ }^{2}$, \\ Jamal-Eddine LazReg ${ }^{2}$ and Gaston M. N'GuéréKata ${ }^{3}$ \\ 1 Laboratory of Mathematics, University of Saïda, \\ P.O. Box 138, Saïda 20000, Algeria \\ 2 Laboratory of Mathematics, Djillali Liabes University of Sidi Bel-Abbes, \\ P.O. Box 89, Sidi Bel-Abbès 22000, Algeria. \\ 3 Department of Mathematics, Morgan State University, \\ 1700 E. Cold Spring Lane, Baltimore M.D. 21252, USA. \\ benchohra@univ-sba.dz, lagregjamal@yahoo.fr, gaston.n'guerekata@morgan.edu
}

\begin{abstract}
This paper deals with some existence and Ulam stability results for some functional differential inclusions of Hilfer and Hilfer-Hadamard type with convex and non-convex right hand side. We employ some multi-valued random fixed point theorems for the existence of random solutions. Next we prove that our problems are generalized UlamHyers-Rassias stable.
\end{abstract}

\section{RESUMEN}

Este artículo estudia algunos resultados de existencia y estabilidad de Ulam para algunas inclusiones funcionales diferenciales de tipos Hilfer y Hilfer-Hadamard con lado derecho convexo y no-convexo. Empleamos algunos teoremas aleatorios de punto fijo multi-valuados para la existencia de soluciones aleatorias. A continuación demostramos que nuestros problemas son Ulam-Hyers-Rassias estables generalizados.

Keywords and Phrases: Functional Random differential inclusion; left-sided Riemann-Liouville integral of fractional order; left-sided Hadamard integral of fractional order; Hilfer fractional derivative; convex; non-convex; Hilfer-Hadamard fractional derivative; existence; Ulam stability; random solution; fixed point.

2010 AMS Mathematics Subject Classification: 26A33. 34A60. 


\section{Introduction}

Fractional calculus is relative to the traditional integer order calculus put forward, which is the order of calculus from integer orders extended to any order of the mathematical promotion. From the theoretical point of view, the fractional differential calculus signal processing order extended to any number from an integer, the ways and means of information processing were extended. Fractional order differential equations have recently been applied in various areas of engineering, mathematics, physics and bio-engineering, and other applied sciences [19, 35]. For some fundamental results in the theory of fractional calculus and fractional differential equations we refer the reader to the monographs of Abbas et al. [7, 8], Kilbas et al. [26] and Zhou [41, 42], the papers by Abbas et al. [1, 4, 5, 9, 10], Benchohra et al. [11], and the references therein.

The nature of a dynamic system in engineering or natural sciences depends on the accuracy of the information we have concerning the parameters that describe that system. If the knowledge about a dynamic system is precise then a deterministic dynamical system arises. Unfortunately in most cases the available data for the description and evaluation of parameters of a dynamic system are inaccurate, imprecise or confusing. In other words, evaluation of parameters of a dynamical system is not without uncertainties. When our knowledge about the parameters of a dynamic system are of statistical nature, that is, the information is probabilistic, the common approach in mathematical modeling of such systems is the use of random differential equations or stochastic differential equations. Random differential equations, as natural extensions of deterministic ones, arise in many applications and have been investigated by many mathematicians. We refer the reader to the monographs $[12,27,37]$.

The stability of functional equations was originally raised by Ulam [38]). next by Hyers [21]. Thereafter, this type of stability is called the Ulam-Hyers stability. In 1978, Rassias [32] provided a remarkable generalization of the Ulam-Hyers stability of mappings by considering variables. The concept of stability for a functional equation arises when we replace the functional equation by an inequality which acts as a perturbation of the equation. Considerable attention has been given to the study of the Ulam-Hyers and Ulam-Hyers-Rassias stability of all kinds of functional equations; one can see the monographs of [8, 22], and the papers of Abbas et al. [1, 2, 3, 4, 6, 9, 10], Petru et al. [29], and Rus [33, 34] discussed the Ulam-Hyers stability for operatorial equations and inclusions. More details from historical point of view, and recent developments of such stabilities are reported in $[23,33]$.

Recently, considerable attention has been given to the existence of solutions of initial and boundary value problems for fractional differential equations with Hilfer fractional derivative; see $[15,16,19,20,24,36,39]$. Motivated by the above papers, in this article we discuss the existence and the Ulam stability of solutions for the following problem of Random Hilfer fractional differential 
inclusions of the form

$$
\left\{\begin{array}{l}
\left(D_{0}^{\alpha, \beta} u\right)(t, w) \in F(t, u(t, w), w) ; t \in I:=[0, T], \\
\left.\left(I_{0}^{1-\gamma} u\right)(t, w)\right|_{t=0}=\phi(w),
\end{array} w \in \Omega,\right.
$$

where $\alpha \in(0,1), \beta \in[0,1], \gamma=\alpha+\beta-\alpha \beta, T>0,(\Omega, \mathcal{A})$ is a measurable space, $\phi: \Omega \rightarrow \mathbb{R}$ is a measurable function, $F: I \times \mathbb{R} \rightarrow \mathcal{P}(\mathbb{R})$ is a given multivalued map, $\mathcal{P}(\mathbb{R})$ is the family of all nonempty subsets of $\mathbb{R}, \mathrm{I}_{0}^{1-\gamma}$ is the left-sided Riemann-Liouville integral of order $1-\gamma$, and $\mathrm{D}_{0}^{\alpha, \beta}$ is the Hilfer fractional derivative of order $\alpha$ and type $\beta$.

Next, we consider the following problem of random Hilfer-Hadamard fractional differential inclusions of the form

$$
\left\{\begin{array}{l}
\left({ }^{\mathrm{H}} \mathrm{D}_{1}^{\alpha, \beta} \mathrm{u}\right)(\mathrm{t}, w) \in \mathrm{G}(\mathrm{t}, \mathrm{u}(\mathrm{t}, w), w) ; \mathrm{t} \in[1, \mathrm{~T}], \\
\left({ }^{\mathrm{H}} \mathrm{I}_{1}^{1-\gamma} \mathrm{u}\right)(1, w)=\phi_{0}(w),
\end{array} w \in \Omega,\right.
$$

where $\alpha \in(0,1), \beta \in[0,1], \gamma=\alpha+\beta-\alpha \beta, T>1, \phi_{0}: \Omega \rightarrow \mathbb{R}$ is a measurable function, $\mathrm{G}:[1, \mathrm{~T}] \times \mathbb{R} \rightarrow \mathcal{P}(\mathbb{R})$ is a given multivalued map, ${ }^{\mathrm{H}} \mathrm{I}_{1}^{1-\gamma}$ is the left-sided Hadamard integral of order $1-\gamma$, and ${ }^{H} D_{1}^{\alpha, \beta}$ is the Hilfer-Hadamard fractional derivative of order $\alpha$ and type $\beta$.

\section{Preliminaries}

Let $\mathrm{C}$ be the Banach space of all continuous functions $v$ from I into $\mathbb{R}$ with the supremum (uniform) norm

$$
\|v\|_{\infty}:=\sup _{\mathrm{t} \in \mathrm{I}}|v(\mathrm{t})| .
$$

As usual, AC(I) denotes the space of absolutely continuous functions from I into $\mathbb{R}$. We denote by $A C^{1}(\mathrm{I})$ the space defined by

$$
\operatorname{AC}^{1}(\mathrm{I}):=\left\{w: I \rightarrow \mathbb{R}: \frac{\mathrm{d}}{\mathrm{dt}} w(\mathrm{t}) \in \mathrm{AC}(\mathrm{I})\right\}
$$

By $L^{1}(\mathrm{I})$, we denote the space of Lebesgue-integrable functions $v: \mathrm{I} \rightarrow \mathbb{R}$ with the norm

$$
\|v\|_{1}=\int_{0}^{T}|v(t)| d t
$$

Let $\mathrm{L}^{\infty}(\mathrm{I})$ be the Banach space of measurable functions $u: I \rightarrow \mathbb{R}$ which are essentially bounded, equipped with the norm

$$
\|u\|_{L^{\infty}}=\inf \{c>0:|u(t)| \leq c, \text { a.e. } t \in I\} .
$$

By $\mathrm{C}_{\gamma}(\mathrm{I})$ and $\mathrm{C}_{\gamma}^{1}(\mathrm{I})$, we denote the weighted spaces of continuous functions defined by

$$
\mathrm{C}_{\gamma}(\mathrm{I})=\left\{w:(0, \mathrm{~T}] \rightarrow \mathbb{R}: \mathrm{t}^{1-\gamma} w(\mathrm{t}) \in \mathrm{C}\right\},
$$


with the norm

$$
\|w\|_{c_{\gamma}}:=\sup _{t \in I}\left|t^{1-\gamma} w(t)\right|
$$

and

with the norm

$$
C_{\gamma}^{1}(\mathrm{I})=\left\{w \in C: \frac{\mathrm{d} w}{\mathrm{dt}} \in \mathrm{C}_{\gamma}\right\}
$$

$$
\|w\|_{C_{\gamma}^{1}}:=\|w\|_{\infty}+\left\|w^{\prime}\right\|_{C_{\gamma}} .
$$

Throughout this paper, we denote $\|w\|_{c_{\gamma}}$ by $\|w\|_{c}$.

For each $u \in \mathrm{C}_{\gamma}$ and $w \in \Omega$, define the set of selections of $\mathrm{F}$ by

$$
\mathrm{S}_{\mathrm{Fou}}(w)=\left\{v: \Omega \rightarrow \mathrm{L}^{1}(\mathrm{I}): v(\mathrm{t}, w) \in \mathrm{F}(\mathrm{t}, \mathrm{u}(\mathrm{t}, w), w) ; \mathrm{t} \in \mathrm{I}\right\}
$$

Let $E$ be a Banach space, and denote $P_{c l}(E)=\{A \in \mathcal{P}(E): A$ closed $\}$, $P_{c p, c}(E)=\{A \in \mathcal{P}(E): A$ compact and convex $\}$.

Consider $\mathrm{H}_{\mathrm{d}}: \mathcal{P}(\mathrm{E}) \times \mathcal{P}(\mathrm{E}) \longrightarrow[0, \infty) \cup\{\infty\}$ given by

$$
H_{d}(A, B)=\max \left\{\sup _{a \in A} d(a, B), \sup _{b \in B} d(A, b)\right\},
$$

where $d(A, b)=\inf _{a \in A} d(a, b), d(a, B)=\inf _{b \in B} d(a, b)$. Then $\left(\mathcal{P}_{b d, c l}(E), H_{d}\right)$ is a Hausdorff metric space.

Definition 1. A multifunction $\mathrm{F}: \Omega \rightarrow \mathrm{E}$ is called $\mathcal{A}$ - measurable if, for any open subset $\mathrm{B}$ of $\mathrm{E}$, the set $\mathrm{F}^{-1}(\mathrm{~B})=\{w \in \Omega: \mathrm{F}(w) \cap \mathrm{B} \neq \emptyset\} \in \mathcal{A}$. Note that if $\mathrm{F}(w) \in \mathcal{P}_{\mathrm{cl}}(\mathrm{E})$ for all $w \in \Omega$, then $\mathrm{F}$ is measurable if and only if $\mathrm{F}^{-1}(\mathrm{D}) \in \mathcal{A}$ for all $\mathrm{D} \in \mathcal{P}_{\mathrm{cl}}(\mathrm{E})$. A measurable operator $\mathrm{u}: \Omega \rightarrow \mathrm{E}$ is called a measurable selector for a measurable multifunction $\mathrm{F}: \Omega \rightarrow \mathrm{E}$, if $\mathrm{u}(\boldsymbol{w}) \in \mathrm{F}(\boldsymbol{w})$. Let $\mathrm{M} \in \mathcal{P}_{\mathrm{cl}}(\mathrm{E})$, then a mapping $\mathrm{f}: \Omega \times \mathrm{M} \rightarrow \mathrm{E}$ is called a random operator if, for each $\mathrm{u} \in \mathrm{M}$, the mapping $\mathrm{f}(., \mathrm{u}): \Omega \rightarrow \mathrm{E}$ is measurable. An operator $\mathrm{u}: \Omega \rightarrow \mathrm{E}$ is said to be a random fixed point of $\mathrm{F}$ if $\mathrm{u}$ is measurable and $\mathrm{u}(\boldsymbol{w}) \in \mathrm{F}(\mathfrak{w}, \mathrm{u}(\boldsymbol{w}))$ for all $\boldsymbol{w} \in \Omega$.

Definition 2. A multifunction $\mathrm{F}: \Omega \times \mathrm{E} \rightarrow \mathcal{P}(\mathrm{E})$ is called Carathéodory if $\mathrm{F}(\cdot, \mathrm{u})$ is measurable for all $\mathrm{u} \in \mathrm{E}$ and $\mathrm{F}(\boldsymbol{w}, \cdot)$ is continuous for all $w \in \Omega$.

Definition 3. A multivalued map $\mathrm{F}: \mathrm{I} \times \mathrm{E} \times \Omega \rightarrow \mathcal{P}_{\mathrm{cp}}(\mathrm{E})$ is said to be random Carathéodory if

(i) $(\mathrm{t}, \mathrm{w}) \longmapsto \mathrm{F}(\mathrm{t}, \mathrm{u}, w)$ is jointly measurable for each $\mathrm{u} \in \mathrm{E}$; and

(ii) $\mathrm{u} \longmapsto \mathrm{F}(\mathrm{t}, \mathrm{u}, \boldsymbol{w})$ is Hausdorff continuous for almost each $\mathrm{t} \in \mathrm{I}, \boldsymbol{w} \in \Omega$.

Definition 4. [17] Let $\mathrm{E}$ be a separable Banach space. If $\mathrm{F}: \mathrm{I} \times \mathrm{E} \rightarrow \mathcal{P}_{\mathrm{cp}}(\mathrm{E})$ is Carathéodory, then the multivalued mapping $(\mathrm{t}, \mathrm{u}(\mathrm{t})) \rightarrow \mathrm{F}(\mathrm{t}, \mathrm{u}(\mathrm{t}))$, is jointly measurable for any measurable $\mathrm{E}$-valued function $\mathrm{u}$ on $\mathrm{I}$. 
Definition 5. A multivalued random operator $\mathrm{N}: \Omega \times \mathrm{E} \rightarrow \mathcal{P}_{\mathrm{cl}}(\mathrm{E})$ is called multivalued random contraction if there is a measurable function $\mathrm{k}: \Omega \rightarrow[0, \infty)$ such that

$$
\mathrm{H}_{\mathrm{d}}(\mathrm{N}(w) \mathrm{u}, \mathrm{N}(w) v) \leq k(w)\|\mathrm{u}-v\|_{\mathrm{E}},
$$

for all $\mathrm{u}, v \in \mathrm{E}$ and $w \in \Omega$, where $\mathrm{k}(w) \in[0,1)$ on $\Omega$.

Now, we give some results and properties of fractional calculus.

Definition 6. [7, 26] The Riemann-Liouville integral of order $r>0$ of a function $w \in \mathrm{L}^{1}(\mathrm{I})$ is defined by

$$
\left(I_{0}^{r} w\right)(t)=\frac{1}{\Gamma(r)} \int_{0}^{t}(t-s)^{r-1} w(s) d s ; \text { for a.e. } t \in I,
$$

where $\Gamma(\cdot)$ is the (Euler's) Gamma function defined by

$$
\Gamma(\xi)=\int_{0}^{\infty} t^{\xi-1} e^{-t} d t ; \xi>0 .
$$

Notice that for all $r, r_{1}, r_{2}>0$ and each $w \in C$, we have $I_{0}^{r} w \in C$, and

$$
\left(I_{0}^{r_{1}} I_{0}^{r_{2}} w\right)(t)=\left(I_{0}^{r_{1}+r_{2}} w\right)(t) ; \text { for a.e. } t \in I \text {. }
$$

Definition 7. [7, 26] The Riemann-Liouville fractional derivative of order $\mathrm{r} \in(0,1]$ of a function $w \in \mathrm{L}^{1}(\mathrm{I})$ is defined by

$$
\begin{aligned}
\left(D_{0}^{r} w\right)(t) & =\left(\frac{d}{d t} I_{0}^{1-r} w\right)(t) \\
& =\frac{1}{\Gamma(1-r)} \frac{d}{d t} \int_{0}^{t}(t-s)^{-r} w(s) d s ; \text { for a.e. } t \in I .
\end{aligned}
$$

Let $r \in(0,1], \gamma \in[0,1)$ and $w \in \mathrm{C}_{1-\gamma}(\mathrm{I})$. Then the following expression leads to the left inverse operator as follows.

$$
\left(D_{0}^{r} I_{0}^{r} w\right)(t)=w(t) ; \text { for all } t \in(0, T] .
$$

Moreover, if $\mathrm{I}_{0}^{1-r} w \in \mathrm{C}_{1-\gamma}^{1}(\mathrm{I})$, then

$$
\left(I_{0}^{r} D_{0}^{r} w\right)(t)=w(t)-\frac{\left(I_{0}^{1-r} w\right)\left(0^{+}\right)}{\Gamma(r)} t^{r-1} ; \text { for all } t \in(0, T] .
$$

Definition 8. [7, 26] The Caputo fractional derivative of order $r \in(0,1]$ of a function $w \in A C(I)$ is defined by

$$
\begin{aligned}
\left({ }^{c} D_{0}^{r} w\right)(t) & =\left(I_{0}^{1-r} \frac{d}{d t} w\right)(t) \\
& =\frac{1}{\Gamma(1-r)} \int_{0}^{t}(t-s)^{-r} \frac{d}{d s} w(s) d s ; \text { for a.e. } t \in I
\end{aligned}
$$


In [19], R. Hilfer studied applications of a generalized fractional operator having the RiemannLiouville and the Caputo derivatives as specific cases (see also [20, 24, 36].

Definition 9. (Hilfer derivative). Let $\alpha \in(0,1), \beta \in[0,1], w \in \mathrm{L}^{1}(\mathrm{I}), \mathrm{I}_{0}^{(1-\alpha)(1-\beta)} \in A C^{1}(\mathrm{I})$. The Hilfer fractional derivative of order $\alpha$ and type $\beta$ of $w$ is defined as

$$
\left(D_{0}^{\alpha, \beta} w\right)(t)=\left(I_{0}^{\beta(1-\alpha)} \frac{d}{d t} I_{0}^{(1-\alpha)(1-\beta)} w\right)(t) ; \text { for a.e. } t \in I \text {. }
$$

Properties. Let $\alpha \in(0,1), \beta \in[0,1], \gamma=\alpha+\beta-\alpha \beta$, and $w \in \mathrm{L}^{1}(\mathrm{I})$.

1. The operator $\left(D_{0}^{\alpha, \beta} w\right)(t)$ can be written as

$$
\left(D_{0}^{\alpha, \beta} w\right)(t)=\left(I_{0}^{\beta(1-\alpha)} \frac{d}{d t} I_{0}^{1-\gamma} w\right)(t)=\left(I_{0}^{\beta(1-\alpha)} D_{0}^{\gamma} w\right)(t) ; \text { for a.e. } t \in I \text {. }
$$

Moreover, the parameter $\gamma$ satisfies

$$
\gamma \in(0,1], \gamma \geq \alpha, \gamma>\beta, 1-\gamma<1-\beta(1-\alpha)
$$

2. The generalization (2.1) for $\beta=0$, coincides with the Riemann-Liouville derivative and for $\beta=1$ with the Caputo derivative.

$$
\mathrm{D}_{0}^{\alpha, 0}=\mathrm{D}_{0}^{\alpha}, \text { and } \mathrm{D}_{0}^{\alpha, 1}={ }^{c} \mathrm{D}_{0}^{\alpha}
$$

3. If $\mathrm{D}_{0}^{\beta(1-\alpha)} w$ exists and in $\mathrm{L}^{1}(\mathrm{I})$, then

$$
\left(D_{0}^{\alpha, \beta} I_{0}^{\alpha} w\right)(t)=\left(I_{0}^{\beta(1-\alpha)} D_{0}^{\beta(1-\alpha)} w\right)(t) ; \text { for a.e. } t \in I \text {. }
$$

Furthermore, if $w \in \mathrm{C}_{\gamma}(\mathrm{I})$ and $\mathrm{I}_{0}^{1-\beta(1-\alpha)} \mathcal{w} \in \mathrm{C}_{\gamma}^{1}(\mathrm{I})$, then

$$
\left(D_{0}^{\alpha, \beta} I_{0}^{\alpha} w\right)(t)=w(t) ; \text { for a.e. } t \in I \text {. }
$$

4. If $\mathrm{D}_{0}^{\gamma} \mathcal{w}$ exists and in $\mathrm{L}^{1}(\mathrm{I})$, then

$$
\left(I_{0}^{\alpha} D_{0}^{\alpha, \beta} w\right)(t)=\left(I_{0}^{\gamma} D_{0}^{\gamma} w\right)(t)=w(t)-\frac{I_{0}^{1-\gamma}\left(0^{+}\right)}{\Gamma(\gamma)} t^{\gamma-1} ; \text { for a.e. } t \in I .
$$

Corolary 1. Let $\mathrm{h} \in \mathrm{C}_{\gamma}(\mathrm{I})$. Then the Cauchy problem

$$
\left\{\begin{array}{l}
\left(D_{0}^{\alpha, \beta} u\right)(t)=h(t) ; t \in I, \\
\left.\left(I_{0}^{1-\gamma} u\right)(t)\right|_{t=0}=\phi,
\end{array}\right.
$$

has a unique solution $\mathrm{u} \in \mathrm{L}^{1}(\mathrm{I})$ given by

$$
u(t)=\frac{\phi}{\Gamma(\gamma)} t^{\gamma-1}+\left(I_{0}^{\alpha} h\right)(t)
$$


From the above corollary, we conclude the following lemma.

Lemma 2.1. Let $\mathrm{F}: \mathrm{I} \times \mathbb{R} \times \Omega \rightarrow \mathcal{P}(\mathbb{R})$ be such that $\mathrm{S}_{\mathrm{Fou}}(\boldsymbol{w}) \subset \mathrm{C}_{\gamma}$ for any $\mathrm{u} \in \mathrm{C}_{\gamma}$. Then problem (1.1) is equivalent to the problem of the solutions of the integral equation

$$
u(t, w)=\frac{\phi(w)}{\Gamma(\gamma)} t^{\gamma-1}+\left(I_{0}^{\alpha} v\right)(t, w)
$$

where $v \in \mathrm{S}_{\mathrm{Fou}}(w)$.

Now, we consider the Ulam stability for the problem (1.1). Let $€>0$ and $\Phi: \mathrm{I} \times \Omega \rightarrow[0, \infty)$ be a continuous function. We consider the following inequalities

$$
\begin{gathered}
\mathrm{H}_{\mathrm{d}}\left(\left(\mathrm{D}_{0}^{\alpha, \beta} \mathrm{u}\right)(\mathrm{t}, w), \mathrm{F}(\mathrm{t}, \mathrm{u}(\mathrm{t}, w), w)\right) \leq \epsilon ; \mathrm{t} \in \mathrm{I}, w \in \Omega . \\
\mathrm{H}_{\mathrm{d}}\left(\left(\mathrm{D}_{0}^{\alpha, \beta} \mathrm{u}\right)(\mathrm{t}, w), \mathrm{F}(\mathrm{t}, \mathrm{u}(\mathrm{t}, w), w)\right) \leq \Phi(\mathrm{t}, w) ; \mathrm{t} \in \mathrm{I}, \boldsymbol{w} \in \Omega . \\
\mathrm{H}_{\mathrm{d}}\left(\left(\mathrm{D}_{0}^{\alpha, \beta} \mathrm{u}\right)(\mathrm{t}, w), \mathrm{F}(\mathrm{t}, \mathrm{u}(\mathrm{t}, w), w)\right) \leq \epsilon \Phi(\mathrm{t}, w) ; \mathrm{t} \in \mathrm{I}, \boldsymbol{w} \in \Omega .
\end{gathered}
$$

Definition 10. [7, 33] The problem (1.1) is Ulam-Hyers stable if there exists a real number $\mathrm{c}_{\mathrm{F}}>0$ such that for each $\epsilon>0$ and for each random solution $\mathrm{u}: \Omega \rightarrow \mathrm{C}_{\gamma}$ of the inequality (2.2) there exists a random solution $v: \Omega \rightarrow \mathrm{C}_{\gamma}$ of (1.1) with

$$
|u(t, w)-v(t, w)| \leq \epsilon c_{F} ; t \in I, w \in \Omega
$$

Definition 11. [7, 33] The problem (1.1) is generalized Ulam-Hyers stable if there exists $\mathfrak{c}_{\mathrm{F}}$ : $\mathrm{C}([0, \infty),[0, \infty))$ with $\mathrm{c}_{\mathrm{F}}(0)=0$ such that for each $\epsilon>0$ and for each random solution $\mathrm{u}: \Omega \rightarrow \mathrm{C}_{\gamma}$ of the inequality (2.2) there exists a random solution $v: \Omega \rightarrow \mathrm{C}_{\gamma}$ of (1.1) with

$$
|u(t, w)-v(t, w)| \leq c_{F}(\epsilon) ; t \in I, w \in \Omega
$$

Definition 12. [7, 33] The problem (1.1) is Ulam-Hyers-Rassias stable with respect to $\Phi$ if there exists a real number $\mathrm{c}_{\mathrm{F}, \Phi}>0$ such that for each $\epsilon>0$ and for each random solution $\mathrm{u}: \Omega \rightarrow \mathrm{C}_{\gamma}$ of the inequality (2.4) there exists a random solution $v: \Omega \rightarrow \mathrm{C}_{\gamma}$ of (1.1) with

$$
|u(t, w)-v(t, w)| \leq \epsilon c_{F, \Phi} \Phi(t, w) ; t \in I, w \in \Omega
$$

Definition 13. [7, 33] The problem (1.1) is generalized Ulam-Hyers-Rassias stable with respect to $\Phi$ if there exists a real number $\mathrm{c}_{\mathrm{F}, \Phi}>0$ such that for each random solution $\mathrm{u}: \Omega \rightarrow \mathrm{C}_{\gamma}$ of the inequality (2.3), there exists a random solution $v: \Omega \rightarrow \mathrm{C}_{\gamma}$ of (1.1) with

$$
|u(t, w)-v(t, w)| \leq c_{F, \Phi} \Phi(t, w) ; t \in I, w \in \Omega
$$

Remark 1. It is clear that

(i) Definition $10 \Rightarrow$ Definition 11, 
(ii) Definition 12 $\Rightarrow$ Definition 13,

(iii) Definition 12 for $\Phi(.,)=.1 \Rightarrow$ Definition 10 .

One can have similar remarks for the inequalities (2.2) and (2.4).

In the sequel, we employ the following random multi-valued fixed point theorems:

Theorem 2.1. [14]] Let $(\Omega, \mathcal{A})$ be a complete $\sigma$-finite measure space, $\mathrm{X}$ be a separable Banach space, $\mathcal{M}(\Omega, \mathrm{X})$ be the space of all measurable $\mathrm{X}$-valued functions defined on $\Omega$, and let $\mathrm{N}: \Omega \times \mathrm{X} \rightarrow$ $\mathcal{P}_{\mathrm{cp}, \mathrm{cv}}(\mathrm{X})$ be a continuous and condensing multi-valued random operator. If the set $\{\mathrm{u} \in \mathcal{M}(\Omega, X):$ $\lambda u \in N(w) u\}$ is bounded for each $\boldsymbol{w} \in \Omega$ and all $\lambda>1$, then $\mathrm{N}(\boldsymbol{w})$ has a random fixed point.

Theorem 2.2. [28] Let $(\Omega, \mathcal{A})$ be a complete $\sigma$-finite measure space, $\mathrm{E}$ a separable Banach space, and let $\mathrm{N}: \Omega \times \mathrm{E} \rightarrow \mathcal{P}_{\mathrm{cl}}(\mathrm{E})$ be a random multi-valued contraction. Then $\mathrm{N}(\boldsymbol{w})$ has a random fixed point.

We recall an integral inequality which based on an iteration argument.

Lemma 2.2. [40] Suppose $\beta>0, \mathrm{a}(\mathrm{t})$ is a nonnegative function locally integrable on $0 \leq \mathrm{t}<\mathrm{T}$ (some $\mathrm{T} \leq+\infty)$ and $\mathrm{g}(\mathrm{t})$ is a nonnegative, nondecreasing continuous function defined on $0 \leq \mathrm{t}<$ $\mathrm{T}, \mathrm{g}(\mathrm{t}) \leq \mathrm{M}$ (constant), and suppose $\mathrm{u}(\mathrm{t})$ is nonnegative and locally integrable on $0 \leq \mathrm{t}<\mathrm{T}$ with

$$
u(t) \leq a(t)+g(t) \int_{0}^{t}(t-s)^{\beta-1} u(s) d s
$$

on this interval. Then

$$
u(t) \leq a(t)+\int_{0}^{t}\left[\sum_{n=1}^{\infty} \frac{(g(t) \Gamma(\beta))^{n}}{\Gamma(n \beta)}(t-s)^{n \beta-1} a(s)\right] d s, 0 \leq t<T .
$$

From the above lemma, we concluded with the following lemma.

Lemma 2.3. Suppose $\beta>0, \mathrm{a}(\mathrm{t}, \boldsymbol{w})$ is a nonnegative function locally integrable on $[0, \mathrm{~T}) \times \Omega$ (some $\mathrm{T} \leq+\infty)$ and $\mathrm{g}(\mathrm{t}, \mathrm{w}$ is a nonnegative, nondecreasing continuous function with respect to $t$ defined on $[0, \mathrm{~T}) \times \Omega, \mathrm{g}(\mathrm{t}, \boldsymbol{w}) \leq \mathrm{M}$ (constant), and suppose $\mathrm{u}(\mathrm{t}, \boldsymbol{w})$ is nonnegative and locally integrable with respect to $t$ on $[0, \mathrm{~T}) \times \Omega$ with

$$
u(t, w) \leq a(t, w)+g(t, w) \int_{0}^{t}(t-s)^{\beta-1} u(s, w) d s
$$

on $[0, \mathrm{~T}) \times \Omega$. Then

$$
u(t, w) \leq a(t, w)+\int_{0}^{t}\left[\sum_{n=1}^{\infty} \frac{(g(t, w) \Gamma(\beta))^{n}}{\Gamma(n \beta)}(t-s)^{n \beta-1} a(s, w)\right] d s, \quad(t, w) \in[0, T) \times \Omega .
$$




\section{Hilfer random fractional differential inclusions}

In this section, we are concerned with the existence and the Ulam-Hyers-Rassias stability for problem (1.1). Let us start by defining what we mean by a random solution of the problem (1.1).

Definition 14. By a random solution of the problem (1.1) we mean a measurable function $\mathrm{u}: \Omega \rightarrow$ $\mathrm{C}_{\gamma}$ that satisfies the condition $\left(\mathrm{I}_{0}^{1-\gamma} \mathrm{u}\right)\left(0^{+}, w\right)=\phi(w)$, and the equation $\left(\mathrm{D}_{0}^{\alpha, \beta} \mathrm{u}\right)(\mathrm{t}, w)=v(\mathrm{t}, w)$ on $\mathrm{I} \times \Omega$, where $v \in \mathrm{S}_{\mathrm{Fou}}(\boldsymbol{w})$.

\subsection{The convex case}

We present now some existence and Ulam stabilities results for the problem (1.1) with convex valued right hand side.

The following hypotheses will be used in the sequel.

$\left(\mathrm{H}_{1}\right)$ The multifunction $\mathrm{F}: \mathrm{I} \times \mathbb{R} \times \Omega \rightarrow \mathcal{P}_{\mathrm{cp}, \mathrm{cv}}(\mathbb{R})$ is random Carathéodory on $\mathrm{I} \times \mathbb{R} \times \Omega$,

$\left(\mathrm{H}_{2}\right)$ There exists a measurable and bounded function $l: \Omega \rightarrow \mathrm{L}^{\infty}(\mathrm{I},[0, \infty))$ satisfying for each $w \in \Omega$,

$$
H_{d}(F(t, u, w), F(t, \bar{u}, w)) \leq t^{1-\gamma} \mathfrak{l}(t, w)|u-\bar{u}| ; \quad \text { for every } t \in I \text { and } \mathfrak{u}, \bar{u} \in \mathbb{R} .
$$

and

$$
d(0, F(t, 0, w)) \leq t^{1-\gamma} l(t, w) ; \text { for } t \in I,
$$

$\left(H_{3}\right)$ There exists $\lambda_{\Phi}>0$ such that for each $t \in I$, and $w \in \Omega$, we have

$$
\int_{0}^{t}\left[\sum_{n=1}^{\infty} \frac{\left(l^{*}\right)^{n}}{\Gamma(n \alpha)}(t-s)^{n \alpha-1} \Phi(s, w)\right] d s \leq \lambda_{\Phi} \Phi(t, w) .
$$

Remark 2. For each $\mathrm{u}: \Omega \rightarrow \mathcal{C}$, the set $\mathrm{S}_{\mathrm{F}, \mathrm{u}}(\boldsymbol{w})$ is nonempty since by $\left(\mathrm{H}_{1}\right), \mathrm{F}$ has a measurable selection (see [13], Theorem III.6).

Remark 3. The hypothesis $\left(\mathrm{H}_{2}\right)$ implies that, for every $\mathrm{t} \in \mathrm{I}, \boldsymbol{u} \in \mathbb{R}$ and $w \in \Omega$, we get

$$
\mathrm{H}_{\mathrm{d}}(\mathrm{F}(\mathrm{t}, \mathrm{u}, w), \mathrm{F}(\mathrm{t}, 0, w)) \leq \mathrm{l}(\mathrm{t}, w)|\mathrm{u}|,
$$

and

$$
\begin{aligned}
\mathrm{H}_{\mathrm{d}}(0, \mathrm{~F}(\mathrm{t}, \mathrm{u}, w)) & \leq \mathrm{H}_{\mathrm{d}}(0, \mathrm{~F}(\mathrm{t}, 0, w))+\mathrm{H}_{\mathrm{d}}(\mathrm{F}(\mathrm{t}, \mathrm{u}, w), \mathrm{F}(\mathrm{t}, 0, w)) \\
& \leq \mathrm{l}(\mathrm{t}, w)(1+|\mathrm{u}|) .
\end{aligned}
$$

Set

$$
l^{*}=\sup _{w \in \Omega}\|l(w)\|_{L^{\infty}} \text { and } \phi^{*}=\sup _{w \in \Omega}|\phi(w)| .
$$


Theorem 3.1. Assume that the hypotheses $\left(\mathrm{H}_{1}\right)$ and $\left(\mathrm{H}_{2}\right)$ hold. Then, the problem (1.1) has a random solution defined on $\mathrm{I} \times \Omega$.

Proof. Define a multivalued operator $\mathrm{N}: \Omega \times \mathrm{C}_{\gamma} \rightarrow \mathcal{P}\left(\mathrm{C}_{\gamma}\right)$ by:

$$
(\mathrm{N}(w) \mathrm{u})(\mathrm{t})=\left\{\mathrm{h}: \Omega \rightarrow \mathrm{C}_{\gamma}: \mathrm{h}(\mathrm{t}, w)=\frac{\phi(w)}{\Gamma(\gamma)} \mathrm{t}^{\gamma-1}+\left(\mathrm{I}_{0}^{\alpha} v\right)(\mathrm{t}, w) ; \mathrm{t} \in \mathrm{I}, \boldsymbol{v} \in \mathrm{S}_{\mathrm{Fou}}(w)\right\}
$$

The map $\phi$ is measurable for all $w \in \Omega$. Again, as the indefinite integral is continuous on $\mathrm{I}$, for each $v \in S_{\text {Fou }}(w)$, then $N(w)$ defines a multivalued mapping $N: \Omega \times C_{\gamma} \rightarrow \mathcal{P}\left(C_{\gamma}\right)$. Thus $u$ is a random solution for the problem (1.1) if and only if $u \in N(w) u$. We shall show that the multivalued operator $\mathrm{N}$ satisfies all conditions of Theorem 2.1. The proof will be given in several steps.

Step 1. $N(w)$ is a multi-valued random operator on $\mathcal{C}$.

Since $\mathrm{F}(\mathrm{t}, \mathrm{u}, w)$ is random Carathéodory, the map $w \rightarrow F(t y, u, w)$ is measurable in view of Definition 4. Similarly, the product $(t-s)^{\alpha-1} v(s, w)$ of a continuous function and a measurable multifunction is again measurable for each $v \in S_{\text {Fou }}(w)$. Further, the integral is a limit of a finite sum of measurable functions, therefore, the map

$$
w \mapsto \frac{\phi(w)}{\Gamma(\gamma)} \mathrm{t}^{\gamma-1}+\int_{0}^{\mathrm{t}} \frac{(\mathrm{t}-\mathrm{s})^{\alpha-1}}{\Gamma(\alpha)} v(\mathrm{t}, w) \mathrm{d} s,
$$

is measurable. As a result, $N(w)$ is a multi-valued random operator on $C_{\gamma}$.

Step 2. $\mathrm{N}(w) u \in \mathcal{P}_{\mathrm{cv}}\left(\mathrm{C}_{\gamma}\right)$ for each $\mathrm{u} \in \mathrm{C}_{\gamma}$.

Indeed, if $h_{1}, h_{2}$ belong to $N(w) u$, then there exist $v_{1}, v_{2} \in S_{\text {Fou }}(w)$ such that for each $t \in I$ and $w \in \Omega$, we have

$$
h_{i}(t, w)=\frac{\phi(w)}{\Gamma(\gamma)} t^{\gamma-1}+\left(I_{0}^{\alpha} v_{i}\right)(t, w) ; i=1,2
$$

Let $0 \leq \mathrm{d} \leq 1$. Then, for each $\mathrm{t} \in \mathrm{I}$ and $w \in \Omega$, we get

$$
\left(d h_{1}+(1-d) h_{2}\right)(t, w)=\frac{\phi(w)}{\Gamma(\gamma)} t^{\gamma-1}+\left(I_{0}^{\alpha}\left[d v_{1}+(1-d) v_{2}\right]\right)(t, w) .
$$

Since $S_{\text {Fou }}(w)$ is convex (because $F$ has convex values), we get

$$
\mathrm{dh}_{1}+(1-\mathrm{d}) \mathrm{h}_{2} \in \mathrm{N}(\mathrm{u}) \text {. }
$$

Step 3. $\mathrm{N}(w)$ is continuous and $\mathrm{N}(w) \mathfrak{u} \in \mathcal{P}_{\mathrm{cp}}\left(\mathrm{C}_{\gamma}\right)$ for each $\mathfrak{u} \in \mathrm{C}_{\gamma}$. The proof of this step will be given in several claims.

Claim 1: $N(w)$ is continuous.

Let $\left\{u_{n}\right\}$ be a sequence such that $u_{n} \rightarrow u$ in $C_{\gamma}$. Then from $\left(H_{2}\right)$, for each $t \in I$ and $w \in \Omega$, we 
have

$$
\begin{aligned}
& H_{d}\left(F\left(t, u_{n}(t, w), w\right), F(t, u(t, w), w)\right) \\
\leq & t^{1-\gamma} l(t, w)\left|u_{n}(t, w)-u(t, w)\right| \\
\leq & l^{*}\left\|u_{n}-u\right\|_{C} \rightarrow 0 \text { as } n \rightarrow \infty
\end{aligned}
$$

Thus, we obtain

$$
H_{d}\left(\mathrm{~F}\left(\mathrm{t}, \mathrm{u}_{\mathrm{n}}(\mathrm{t}, w), w\right), \mathrm{F}(\mathrm{t}, \mathrm{u}(\mathrm{t}, w), w)\right) \rightarrow 0 \text { as } \mathrm{n} \rightarrow \infty \text {. }
$$

Claim 2: $\mathrm{N}(w)$ maps bounded sets into bounded sets in $\mathrm{C}_{\gamma}$.

Let $\mathrm{B}_{\eta^{*}}=\left\{u \in C_{\gamma}:\|u\|_{c} \leq \eta^{*}\right\}$ be bounded set in $C_{\gamma}$, and $u \in B_{\eta^{*}}$. Then for each $h \in N(w) u$, there exists $v \in S_{\text {Fou }}(w)$ such that

$$
h(t, w)=\frac{\phi(w)}{\Gamma(\gamma)} t^{\gamma-1}+\left(I_{0}^{\alpha} v\right)(t, w)
$$

By $\left(\mathrm{H}_{2}\right)$, for each $t \in \mathrm{I}$ and $w \in \Omega$, we obtain

$$
\begin{aligned}
\left|t^{1-\gamma} h(t, w)\right| & \leq \frac{|\phi(w)|}{\Gamma(\gamma)}+T^{1-\gamma} \int_{0}^{t} \frac{(t-s)^{\alpha-1}}{\Gamma(\alpha)}|v(s, w)| \mathrm{d} s \\
& \leq \frac{|\phi(w)|}{\Gamma(\gamma)}+T^{1-\gamma} \int_{0}^{t} \frac{(t-s)^{\alpha-1}}{\Gamma(\alpha)}\left|s^{1-\gamma} l(s, w)(1+v(s, w))\right| \mathrm{d} s \\
& \leq \frac{\phi^{*}}{\Gamma(\gamma)}+l^{*} T^{1-\gamma} \int_{0}^{t} \frac{(t-s)^{\alpha-1}}{\Gamma(\alpha)}\left(T^{1-\gamma}+\|v(s, w)\|_{C}\right) \mathrm{d} s \\
& \leq \frac{\phi^{*}}{\Gamma(\gamma)}+\frac{l^{*} T^{1+\alpha-\gamma}}{\Gamma(1+\alpha)}\left(T^{1-\gamma}+\eta^{*}\right):=\ell .
\end{aligned}
$$

Claim 3: $\mathrm{N}(w)$ maps bounded sets into equicontinuous sets in $\mathrm{C}_{\gamma}$.

Let $\left.t_{1}\right), t_{2} \in I, t_{1}<t_{2}$, and let $B_{\eta^{*}}$ be a bounded set of $C_{\gamma}$ as in claim 2, and let $u \in B_{\eta^{*}}$ and $h \in N(w) u$. Then, there exists $v \in S_{\text {Fou }}(w)$ such that for each $w \in \Omega$, we get

$$
\begin{aligned}
\left|t_{2}^{1-\gamma} h\left(t_{2}, w\right)-t_{1}^{1-\gamma} h\left(t_{1}, w\right)\right| \leq & \frac{l^{*} T^{1-\gamma+\alpha}}{\Gamma(1+\alpha)}\left(t_{2}-t_{1}\right)^{\alpha} \\
& +\frac{l^{*}\left(T^{1-\gamma}+\eta^{*}\right)}{\Gamma(\alpha)} \int_{0}^{t_{1}} \mid t_{2}^{1-\gamma}\left(t_{2}-s\right)^{\alpha-1}-t_{1}^{1-\gamma}\left(t_{1}-s\right)^{\alpha-1} d s .
\end{aligned}
$$

As $t_{1} \rightarrow t_{2}$, the right-hand side of the above inequality tends to zero. As a consequence of claims 1 to 3, together with the Arzela-Ascoli theorem, we can conclude that $N(w)$ is continuous and completely continuous multi-valued random operator.

Step 4: The set $\mathcal{E}:=\left\{\mathfrak{u} \in \mathrm{C}_{\gamma}: \lambda \mathrm{u} \in \mathrm{N}(\boldsymbol{w}) \mathrm{u}\right\}$ is bounded for some $\lambda>1$.

Let $u \in \mathrm{C}_{\gamma}$ be arbitrary and let $w \in \Omega$ be fixed such that $\lambda u \in N(w) u$ for all $\lambda>1$. Then, there exists $v \in S_{\text {Fou }}(w)$ such that for each $t \in I$, we have

$$
u(t, w)=\frac{\phi(w)}{\lambda \Gamma(\gamma)} t^{\gamma-1}+\lambda^{-1}\left(I_{0}^{\alpha} v\right)(t, w)
$$


This implies by $\left(\mathrm{H}_{2}\right)$ that, for each $\mathrm{t} \in \mathrm{I}$, we get

$$
\begin{aligned}
\left|t^{1-\gamma} u(t, w)\right| & \leq \frac{\phi^{*}}{\Gamma(\gamma)}+\int_{0}^{t} \frac{(t-s)^{\alpha-1}}{\Gamma(\alpha)} l(s, w)\left(T^{1-\gamma}+\left|s^{1-\gamma} v(s, w)\right|\right) d s \\
& \leq \frac{\phi^{*}}{\Gamma(\gamma)}+\frac{l^{*} T^{1-\gamma+\alpha}}{\Gamma(1+\alpha)}+l^{*} \int_{0}^{t} \frac{(t-s)^{\alpha-1}}{\Gamma(\alpha)}\left|s^{1-\gamma} v(s, w)\right| d s
\end{aligned}
$$

From Lemma 2.3 , for each $(t, w) \in[0, T) \times \Omega$, we have

$$
\begin{aligned}
\left|t^{1-\gamma} u(t, w)\right| & \leq\left[\frac{\phi^{*}}{\Gamma(\gamma)}+\frac{l^{*} T^{1-\gamma+\alpha}}{\Gamma(1+\alpha)}\right]\left[1+\int_{0}^{t}\left[\sum_{n=1}^{\infty} \frac{\left(l^{*}\right)^{n}}{\Gamma(n \alpha)}(t-s)^{n \alpha-1}\right] d s\right] \\
& \leq\left[\frac{\phi^{*}}{\Gamma(\gamma)}+\frac{l^{*} T^{1-\gamma+\alpha}}{\Gamma(1+\alpha)}\right]\left[1+\sum_{n=1}^{\infty} \frac{T^{n \alpha}}{\Gamma(1+n \alpha)}\right]:=M .
\end{aligned}
$$

Thus, for all $\mathrm{t} \in \mathrm{I}$ and $w \in \Omega$, we obtain $\|\mathrm{u}\|_{\infty} \leq \mathrm{M}$.

As a consequence of steps 1 to 4, together with the Theorem 2.1, $\mathrm{N}$ has a random fixed point $\mathrm{u}$ which is a random solution to problem (1.1).

Now, we are concerned with the generalized Ulam-Hyers-Rassias stability of our problem (1.1).

Theorem 3.2. Assume that the hypotheses $\left(\mathrm{H}_{1}\right)-\left(\mathrm{H}_{3}\right)$ hold. Then the problem (1.1) is generalized Ulam-Hyers-Rassias stable.

Proof. Let $u$ be a random solution of the inequality (2.3), and let us assume that $v$ is a random solution of problem (1.1). Thus, we have

$$
v(t, w)=\frac{\phi(w)}{\Gamma(\gamma)} t^{\gamma-1}+\int_{0}^{t}(t-s)^{\alpha-1} \frac{f_{v}(s, w)}{\Gamma(\alpha)} d s
$$

where $f_{v} \in S_{\text {Fov }}(w)$. From the inequality (2.3) for each $t \in I$, and $w \in \Omega$, we have

$$
\left|u(t, w)-\frac{\phi(w)}{\Gamma(\gamma)} t^{\gamma-1}-\int_{0}^{t}(t-s)^{\alpha-1} \frac{f(s, w)}{\Gamma(\alpha)} d s\right| \leq\left(I_{0}^{\alpha} \Phi\right)(t, w)
$$

where $f \in S_{\text {Fou }}(w)$. From hypotheses $\left(H_{2}\right)$ and $\left(H_{3}\right)$, for each $t \in I$, and $w \in \Omega$, we get

$$
\begin{aligned}
|u(t, w)-v(t, w)| & \leq\left|u(t, w)-\frac{\phi(w)}{\Gamma(\gamma)} t^{\gamma-1}-\int_{0}^{t}(t-s)^{\alpha-1} \frac{f(s, w)}{\Gamma(\alpha)} d s\right| \\
& +\int_{0}^{t}(t-s)^{\alpha-1} \frac{\left|f(s, w)-f_{v}(s, w)\right|}{\Gamma(\alpha)} d s \\
& \leq\left(I_{0}^{\alpha} \Phi\right)(t, w)+\frac{l^{*} T^{1-\gamma}}{\Gamma(\alpha)} \int_{0}^{t}(t-s)^{\alpha-1}|u(s, w)-v(s, w)| d s
\end{aligned}
$$


From Lemma 2.3, we obtain

$$
\begin{aligned}
\|u(t, w)-v(t, w)\| & \leq \frac{\lambda_{\Phi}}{l^{*}}\left[\Phi(t, w)+\int_{0}^{t}\left[\sum_{n=1}^{\infty} \frac{\left(l^{*}\right)^{n}}{\Gamma(n \alpha)}(t-s)^{n \alpha-1} \Phi(s, w)\right] d s\right] \\
& \leq \frac{\lambda_{\Phi}}{l^{*}}\left[1+\lambda_{\Phi}\right] \Phi(t, w) \\
& :=c_{F, \Phi} \Phi(t, w) .
\end{aligned}
$$

Finally, the problem (1.1) is generalized Ulam-Hyers-Rassias stable.

\subsection{The Non-convex case}

We present now some existence and Ulam stabilities results for the problem (1.1) with non-convex valued right hand side.

The following hypotheses will be used in the sequel.

$\left(\mathrm{H}_{01}\right)$ The multifunction $\mathrm{F}: \mathrm{I} \times \mathbb{R} \times \Omega \rightarrow \mathcal{P}_{\mathrm{cp}}(\mathbb{R})$ is random Carathéodory on $\mathrm{I} \times \mathbb{R} \times \Omega$,

$\left(\mathrm{H}_{02}\right)$ There exists a measurable and bounded function $l: \Omega \rightarrow \mathrm{L}^{\infty}(\mathrm{I},[0, \infty))$ satisfying for each $w \in \Omega$,

$$
H_{d}(F(t, u, w), F(t, \bar{u}, w)) \leq t^{1-\gamma} \mathfrak{l}(t, w)|u-\bar{u}| ; \quad \text { for every } t \in I \text { and } u, \bar{u} \in \mathbb{R} .
$$

Set

$$
l^{*}=\sup _{w \in \Omega}\|l(w)\|_{L^{\infty}} .
$$

Now, we shall prove the following theorem concerning the existence of random solutions of problem (1.1).

Theorem 3.3. Assume that the hypotheses $\left(\mathrm{H}_{01}\right)$ and $\left(\mathrm{H}_{02}\right)$ hold. If

$$
\frac{l^{*} T^{1+\alpha-\gamma}}{\Gamma(1+\alpha)}<1
$$

Then the problem (1.1) has at least one random solution defined on $\mathrm{I} \times \Omega$.

Proof. Let $\mathrm{N}: \Omega \times \mathrm{C}_{\gamma} \rightarrow \mathcal{P}\left(\mathrm{C}_{\gamma}\right)$ be the multivalued operator defined in (3.1). We know that $\mathrm{N}(w)$ is a multi-valued random operator on $\mathrm{C}_{\gamma}$. We shall show that the multivalued operator $\mathrm{N}$ satisfies all conditions of Theorem 2.2. The proof will be given in two steps. 
Step 1. $\mathrm{N}(w) u \in \mathcal{P}_{\mathrm{cl}}\left(\mathrm{C}_{\gamma}\right)$ for each $\mathrm{u} \in \mathrm{C}_{\gamma}$. let $\left\{u_{n}\right\}_{n \geq 0} \in N(w) u$ such that $u_{n} \longrightarrow \tilde{u}$ in $C_{\gamma}$. Then, $\tilde{u} \in C_{\gamma}$ and there exists $f_{n}(\cdot, \cdot, \cdot) \in S_{\text {Fou }}(w)$ be such that, for each $t \in I$ and $w \in \Omega$, we have

$$
u_{n}(t, w)=\frac{\phi(w)}{\Gamma(\gamma)} t^{\gamma-1}+\left(I_{0}^{\alpha} f_{n}\right)(t, w)
$$

Using the fact that $F$ has compact values and from $\left(\mathrm{H}_{01}\right)$, we may pass to a subsequence if necessary to get that $f_{n}(\cdot, \cdot, \cdot)$ converges to $f$ in $L^{1}(I)$, and hence $f \in S_{\text {Fou }}(w)$. Then, for each $t \in I$ and $w \in \Omega$, we get

$$
\mathrm{u}_{\mathrm{n}}(\mathrm{t}, w) \longrightarrow \tilde{\mathrm{u}}(\mathrm{t}, w)=\frac{\phi(w)}{\Gamma(\gamma)} \mathrm{t}^{\gamma-1}+\left(\mathrm{I}_{0}^{\alpha} \mathrm{f}\right)(\mathrm{t}, w)
$$

So, $\tilde{u} \in N(w) u$.

Step 2. There exists $0 \leq \lambda<1$ such that, for each $w \in \Omega$,

$$
\mathrm{H}_{\mathrm{d}}(\mathrm{N}(w) \mathrm{u}, \mathrm{N}(w) \overline{\mathrm{u}}) \leq \lambda\|\mathrm{u}-\overline{\mathrm{u}}\|_{\mathrm{c}} \text { for each } \mathrm{u}, \overline{\mathrm{u}} \in \mathrm{C}_{\gamma} \text {. }
$$

Let $u, \bar{u} \in C_{\gamma}$ and $h \in N(w) u$. Then, there exists $f(t, w) \in F(t, u(t, w), w)$ such that for each $t \in I$ and $w \in \Omega$, we have

$$
h(t, w)=\frac{\phi(w)}{\Gamma(\gamma)} t^{\gamma-1}+\left(I_{0}^{\alpha} f\right)(t, w)
$$

From $\left(\mathrm{H}_{02}\right)$ it follows that

$$
H_{d}(F(t, u(t, w), w), F(t, \bar{u}(t, w), w)) \leq t^{1-\gamma} l(t, w)|u(t, w)-\bar{u}(t, w)|
$$

Hence, there exists $v \in S_{\text {Fou }}$ such that

$$
|f(t, w)-v(t, w)| \leq t^{1-\gamma} l(t, w)|u(t, w)-\bar{u}(t, w)| .
$$

Consider $\mathrm{U}: \mathrm{I} \times \Omega \rightarrow \mathcal{P}(\mathbb{R})$ given by

$$
\mathrm{u}(\mathrm{t}, w)=\left\{v(\mathrm{t}, w) \in \mathbb{R}:|\mathrm{f}(\mathrm{t}, w)-v(\mathrm{t}, w)| \leq \mathrm{t}^{1-\gamma} \mathrm{l}(\mathrm{t}, w)|\mathrm{u}(\mathrm{t}, w)-\overline{\mathrm{u}}(\mathrm{t}, w)|\right\} .
$$

Since the multivalued operator $\mathrm{u}(\mathrm{t}, w)=\mathrm{U}(\mathrm{t}, w) \cap \mathrm{F}(\mathrm{t}, \overline{\mathrm{u}}(\mathrm{t}, w), w)$ is measurable (see Proposition III.4 in [13]), there exists a function $\bar{f}(t, w)$ which is a measurable selection for $\bar{u}$. So, $\bar{f}(t, w) \in$ $\mathrm{F}(\mathrm{t}, \overline{\mathrm{u}}(\mathrm{t}, w), w)$, and for each $\mathrm{t} \in \mathrm{I}$ and $w \in \Omega$, we get

$$
|f(t, w)-\bar{f}(t, w)| \leq t^{1-\gamma} \mathfrak{l}(t, w)|u(t, w)-\bar{u}(t, w)| .
$$

Let us define for each $\mathrm{t} \in \mathrm{I}$ and $w \in \Omega$,

$$
\bar{h}(t, w)=\frac{\phi(w)}{\Gamma(\gamma)} t^{\gamma-1}+\left(I_{0}^{\alpha} \bar{f}\right)(t, w) .
$$


Then for each $\mathrm{t} \in \mathrm{I}$ and $w \in \Omega$, we obtain

$$
\begin{aligned}
\left|t^{1-\gamma} h(t, w)-t^{1-\gamma} \bar{h}(t, w)\right| & \leq t^{1-\gamma} I_{0}^{\alpha}|f(t, w)-\bar{f}(t, w)| \\
& \leq \frac{T^{1-\gamma}}{\Gamma(\alpha)} \int_{0}^{t}(t-s)^{\alpha-1} l(s, w)\left|s^{1-\gamma} u(s, w)-s^{1-\gamma} \bar{u}(s, w)\right| d s \\
& \leq \frac{l^{*} T^{1-\gamma}\|u-\bar{u}\|_{C}}{\Gamma(\alpha)} \int_{0}^{t}(t-s)^{\alpha-1} d s .
\end{aligned}
$$

Hence

$$
\|\mathrm{h}-\overline{\mathrm{h}}\|_{\mathrm{C}} \leq \frac{\mathrm{l}^{*} \mathrm{~T}^{1+\alpha-\gamma}}{\Gamma(1+\alpha)}\|\mathrm{u}-\overline{\mathrm{u}}\|_{\mathrm{C}} .
$$

By an analogous relation, obtained by interchanging the roles of $u$ and $\bar{u}$, it follows that

$$
\mathrm{H}_{\mathrm{d}}(\mathrm{N}(w) \mathrm{u}, \mathrm{N}(w) \overline{\mathrm{u}}) \leq \frac{\mathrm{l}^{*} T^{1+\alpha-\gamma}}{\Gamma(1+\alpha)}\|\mathrm{u}-\overline{\mathrm{u}}\|_{\mathrm{c}} .
$$

So by (3.2), $\mathrm{N}$ is random contraction and thus, by Theorem 2.2, $\mathrm{N}$ has a random fixed point $\mathrm{u}$ which is a random solution to problem (1.1).

Now, we can show the following generalized Ulam-Hyers-Rassias stability result.

Theorem 3.4. Assume that the hypotheses $\left(\mathrm{H}_{01}\right),\left(\mathrm{H}_{02}\right),\left(\mathrm{H}_{3}\right)$ and the condition (3.2) hold, then the problem (1.1) is generalized Ulam-Hyers-Rassias stable.

\section{Hilfer-Hadamard fractional random differential inclusions}

Now, we are concerned with the existence and the Ulam-Hyers-Rassias stability for problem (1.2).

Set $C:=C([1, T])$. Denote the weighted space of continuous functions defined by

$$
\mathrm{C}_{\gamma, \ln }([1, \mathrm{~T}])=\left\{w(\mathrm{t}):(\ln \mathrm{t})^{1-\gamma} \mathcal{w}(\mathrm{t}) \in \mathrm{C}\right\},
$$

with the norm

$$
\|w\|_{C_{\gamma, \ln }}:=\sup _{t \in[1, T]}\left|(\ln t)^{1-r} \mathcal{w}(t)\right|
$$

Let us recall some definitions and properties of Hadamard fractional integration and differentiation. We refer to $[18,26]$ for a more detailed analysis.

Definition 15. [18, 26] (Hadamard fractional integral). The Hadamard fractional integral of order $\mathrm{q}>0$ for a function $\mathrm{g} \in \mathrm{L}^{1}([1, \mathrm{~T}])$, is defined as

$$
\left({ }^{\mathrm{H}} \mathrm{I}_{1}^{\mathrm{q}} \mathrm{g}\right)(\mathrm{x})=\frac{1}{\Gamma(\mathrm{q})} \int_{1}^{\mathrm{x}}\left(\ln \frac{\mathrm{x}}{\mathrm{s}}\right)^{\mathrm{q}-1} \frac{\mathrm{g}(\mathrm{s})}{\mathrm{s}} \mathrm{ds},
$$

provided the integral exists. 
Example 1. Let $0<\mathrm{q}<1$. Then

$$
{ }^{\mathrm{H}} \mathrm{I}_{1}^{\mathrm{q}} \ln \mathrm{t}=\frac{1}{\Gamma(2+\mathrm{q})}(\ln \mathrm{t})^{1+\mathrm{q}} \text {, for a.e. } \mathrm{t} \in[0, e] .
$$

Set

$$
\delta=x \frac{d}{d x}, q>0, n=[q]+1,
$$

and

$$
A C_{\delta}^{n}:=\left\{u:[1, T] \rightarrow E: \delta^{n-1}[u(x)] \in A C(I)\right\} .
$$

Analogous to the Riemann-Liouville fractional calculus, the Hadamard fractional derivative is defined in terms of the Hadamard fractional integral in the following way:

Definition 16. [18, 26] (Hadamard fractional derivative). The Hadamard fractional derivative of order $\mathbf{q}>0$ applied to the function $w \in A C_{\delta}^{n}$ is defined as

$$
\left({ }^{\mathrm{H}} \mathrm{D}_{1}^{\mathrm{q}} w\right)(\mathrm{x})=\delta^{\mathrm{n}}\left({ }^{\mathrm{H}} \mathrm{I}_{1}^{\mathrm{n}-\mathrm{q}} w\right)(\mathrm{x}) .
$$

In particular, if $q \in(0,1]$, then

$$
\left({ }^{\mathrm{H}} \mathrm{D}_{1}^{\mathrm{q}} w\right)(\mathrm{x})=\delta\left({ }^{\mathrm{H}} \mathrm{I}_{1}^{1-\mathrm{q}} w\right)(\mathrm{x}) .
$$

Example 2. Let $0<\mathrm{q}<1$. Then

$$
{ }^{H} D_{1}^{q} \ln t=\frac{1}{\Gamma(2-q)}(\ln t)^{1-q}, \text { for a.e. } t \in[0, e] .
$$

It has been proved (see e.g. Kilbas [[25], Theorem 4.8]) that in the space $\mathrm{L}^{1}(\mathrm{I}, \mathrm{E})$, the Hadamard fractional derivative is the left-inverse operator to the Hadamard fractional integral, i.e.

$$
\left({ }^{\mathrm{H}} \mathrm{D}_{1}^{\mathrm{q}}\right)\left({ }^{\mathrm{H}} \mathrm{I}_{1}^{\mathrm{q}} w\right)(\mathrm{x})=w(x) .
$$

From Theorem 2.3 of [26], we have

$$
\left({ }^{\mathrm{H}} \mathrm{I}_{1}^{\mathrm{q}}\right)\left({ }^{\mathrm{H}} \mathrm{D}_{1}^{\mathrm{q}} w\right)(\mathrm{x})=w(\mathrm{x})-\frac{\left({ }^{\mathrm{H}} \mathrm{I}_{1}^{1-\mathrm{q}} w\right)(1)}{\Gamma(\mathrm{q})}(\ln x)^{\mathrm{q}-1} .
$$

Analogous to the Hadamard fractional calculus, the Caputo-Hadamard fractional derivative is defined in the following way:

Definition 17. (Caputo-Hadamard fractional derivative). The Caputo-Hadamard fractional derivative of order $\mathrm{q}>0$ applied to the function $w \in A C_{\delta}^{n}$ is defined as

$$
\left({ }^{H c} D_{1}^{q} w\right)(x)=\left({ }^{H} I_{1}^{n-q} \delta^{n} w\right)(x) .
$$


In particular, if $q \in(0,1]$, then

$$
\left({ }^{\mathrm{Hc}} \mathrm{D}_{1}^{\mathrm{q}} w\right)(\mathrm{x})=\left({ }^{\mathrm{H}} \mathrm{I}_{1}^{1-\mathrm{q}} \delta w\right)(\mathrm{x}) .
$$

From the Hadamard fractional integral, the Hilfer-Hadamard fractional derivative (introduced for the first time in [30]) is defined in the following way:

Definition 18. (Hilfer-Hadamard fractional derivative). Let $\alpha \in(0,1), \beta \in[0,1], \gamma=\alpha+\beta-$ $\alpha \beta, w \in \mathrm{L}^{1}(\mathrm{I})$, and ${ }^{\mathrm{H}} \mathrm{I}_{1}^{(1-\alpha)(1-\beta)} w \in \mathrm{AC}^{1}(\mathrm{I})$. The Hilfer-Hadamard fractional derivative of order $\alpha$ and type $\beta$ applied to the function $w$ is defined as

$$
\begin{aligned}
\left({ }^{\mathrm{H}} \mathrm{D}_{1}^{\alpha, \beta} w\right)(\mathrm{t}) & =\left({ }^{\mathrm{H}} \mathrm{I}_{1}^{\beta(1-\alpha)}\left({ }^{\mathrm{H}} \mathrm{D}_{1}^{\gamma} w\right)\right)(\mathrm{t}) \\
& =\left({ }^{\mathrm{H}} \mathrm{I}_{1}^{\beta(1-\alpha)} \delta\left({ }^{\mathrm{H}} \mathrm{I}_{1}^{1-\gamma} w\right)\right)(\mathrm{t}) ; \text { for a.e. } \mathrm{t} \in[1, \mathrm{~T}] .
\end{aligned}
$$

This new fractional derivative (4.1) may be viewed as interpolating the Hadamard fractional derivative and the Caputo-Hadamard fractional derivative. Indeed for $\beta=0$ this derivative reduces to the Hadamard fractional derivative and when $\beta=1$, we recover the Caputo-Hadamard fractional derivative.

$$
{ }^{\mathrm{H}} \mathrm{D}_{1}^{\alpha, \mathrm{O}}={ }^{\mathrm{H}} \mathrm{D}_{1}^{\alpha} \text {, and }{ }^{\mathrm{H}} \mathrm{D}_{1}^{\alpha, 1}={ }^{\mathrm{Hc}} \mathrm{D}_{1}^{\alpha} \text {. }
$$

From Theorem 21 in [31], we concluded the following lemma

Lemma 4.1. Let $\mathrm{G}:[1, \mathrm{~T}] \times \mathbb{R} \times \Omega \rightarrow \mathcal{P}(\mathbb{R})$ be such that $\mathrm{S}_{\mathrm{Gou}}(\mathcal{w}) \in \mathrm{C}_{\gamma, \ln }([1, \mathrm{~T}])$ for any $\mathrm{u}(\cdot, \mathcal{w}) \in$ $\mathrm{C}_{\gamma, \ln }([1, \mathrm{~T}])$. Then problem (1.2) is equivalent to the following volterra integral equation

$$
\mathrm{u}(\mathrm{t}, w)=\frac{\phi_{0}(w)}{\Gamma(\gamma)}(\ln \mathrm{t})^{\gamma-1}+\left({ }^{\mathrm{H}} \mathrm{I}_{1}^{\alpha} \mathrm{g}(\cdot, w)\right)(\mathrm{t}) ; w \in \Omega
$$

where $\mathrm{g} \in \mathrm{S}_{\mathrm{Gou}}(w)$.

Definition 19. By a random solution of the problem (1.2) we mean a measurable function $\mathfrak{u} \in$ $\mathrm{C}_{\gamma, \ln }$ that satisfies the condition $\left({ }^{\mathrm{H}} \mathrm{I}_{1}^{1-\gamma} \mathrm{u}\right)\left(1^{+}, w\right)=\phi_{0}(w)$, and the equation $\left({ }^{\mathrm{H}} \mathrm{D}_{1}^{\alpha, \beta} \mathrm{u}\right)(\mathrm{t}, w)=$ $\mathrm{g}(\mathrm{t}, w)$ on $[1, \mathrm{~T}] \times \Omega$, where $\mathrm{g} \in \mathrm{S}_{\mathrm{Gou}}(w)$.

Now we give (without proof) existence and Ulam slability results for problem (1.2). The following hypotheses will be used in the sequel.

$\left(\mathrm{H}_{1}^{\prime}\right)$ The multifunction $\mathrm{G}:[1, \mathrm{~T}] \times \mathbb{R} \times \Omega \rightarrow \mathcal{P}_{\mathrm{cp}, \mathrm{cv}}(\mathbb{R})$ is random Carathéodory,

$\left(H_{2}^{\prime}\right)$ There exists a measurable and bounded function $l: \Omega \rightarrow L^{\infty}([1, T],[0, \infty))$ satisfying for each $w \in \Omega$,

$$
H_{d}(G(t, u, w), G(t, \bar{u}, w)) \leq t^{1-\gamma} \mathfrak{l}(t, w)|u-\bar{u}| ; \text { for every } t \in[1, T] \text { and } u, \bar{u} \in \mathbb{R} .
$$

and

$$
\mathrm{d}(0, \mathrm{G}(\mathrm{t}, 0, w)) \leq(\ln \mathrm{t})^{1-\gamma} \mathrm{l}(\mathrm{t}, w) ; \text { for } \mathrm{t} \in[1, \mathrm{~T}]
$$


$\left(H_{3}^{\prime}\right)$ There exists $\lambda_{\Phi}>0$ such that for each $t \in[1, T]$, and $w \in \Omega$, we have

$$
\int_{1}^{t}\left[\sum_{n=1}^{\infty} \frac{\left(l^{*}\right)^{n}}{\Gamma(n \alpha)}\left(\ln \frac{t}{s}\right)^{n \alpha-1} \Phi(s, w)\right] \frac{d s}{s} \leq \lambda_{\Phi} \Phi(t, w) .
$$

Theorem 4.1. Assume that the hypotheses $\left(\mathrm{H}_{1}^{\prime}\right)$ and $\left(\mathrm{H}_{2}^{\prime}\right)$ hold. Then, the problem (1.1) has a random solution defined on $[1, \mathrm{~T}] \times \Omega$. Moreover; if the hypothesis $\left(\mathrm{H}_{3}^{\prime}\right)$ holds, then the problem (1.1) is generalized Ulam-Hyers-Rassias stable.

Finally, we give (without proof) existence and Ulam stability results for problem (1.2) with nonconvex valued right hand side. The following hypotheses will be used in the sequel.

$\left(H_{01}^{\prime}\right)$ The multifunction $G:[1, T] \times \mathbb{R} \times \Omega \rightarrow \mathcal{P}_{c p}(\mathbb{R})$ is random Carathéeodory on $[1, T] \times \mathbb{R} \times \Omega$,

$\left(\mathrm{H}_{02}^{\prime}\right)$ There exists a measurable and bounded function $p: \Omega \rightarrow \mathrm{L}^{\infty}([1, \mathrm{~T}],[0, \infty))$ satisfying for each $w \in \Omega$,

$$
H_{d}(G(t, u, w), G(t, \bar{u}, w)) \leq(\ln t)^{1-\gamma} p(t, w)|u-\bar{u}| ; \quad \text { for every } t \in[1, T] \text { and } u, \bar{u} \in \mathbb{R} .
$$

Set

$$
l^{*}=\sup _{w \in \Omega}\|l(w)\|_{L^{\infty}} .
$$

Theorem 4.2. Assume that the hypotheses $\left(\mathrm{H}_{01}^{\prime}\right)$ and $\left(\mathrm{H}_{02}^{\prime}\right)$ hold. If

$$
\frac{l^{*}(\ln T)^{1+\alpha-\gamma}}{\Gamma(1+\alpha)}<1
$$

then the problem (1.2) has at least one random solution defined on $[1, \mathrm{~T}] \times \Omega$. Moreover, if the hypothesis $\left(\mathrm{H}_{3}^{\prime}\right)$ holds, then the problem (1.2) is generalized Ulam-Hyers-Rassias stable.

\section{$5 \quad$ Examples}

Let $\Omega=(-\infty, 0)$ be equipped with the usual $\sigma$-algebra consisting of Lebesgue measurable subsets of $(-\infty, 0)$.

Example 1. Consider Hilfer fractional differential inclusion of the form

$$
\left\{\begin{array}{l}
\left(D_{0}^{\frac{1}{2}}, \frac{1}{2} u\right)(t, w) \in F(t, u(t, w), w) ; t \in[0,1], \quad w \in \Omega \\
\left(I_{0}^{\frac{1}{4}} u\right)(0, w)=1
\end{array}\right.
$$

where

$$
\mathrm{F}(\mathrm{t}, \mathrm{u}(\mathrm{t}, w), w)=\left\{v: \Omega \rightarrow \mathrm{C}([0,1], \mathbb{R}):\left|\mathrm{f}_{1}(\mathrm{t}, \mathrm{u}(\mathrm{t}, w), w)\right| \leq|v(w)| \leq\left|\mathrm{f}_{2}(\mathrm{t}, \mathrm{u}(\mathrm{t}, w), w)\right|\right\}
$$


$\mathrm{t} \in[0,1], w \in \Omega$, with $f_{1}, f_{2}:[0,1] \times \mathbb{R} \times \Omega \rightarrow \mathbb{R}$, such that

$$
f_{1}(t, u(t, w), w)=\frac{t^{2} u}{\left(1+w^{2}+|u|\right) e^{10+t}}
$$

and

$$
f_{2}(t, u(t, w), w)=\frac{t^{2} u}{\left(1+w^{2}\right) e^{10+t}} .
$$

Set $\alpha=\beta=\frac{1}{2}$, then $\gamma=\frac{3}{4}$. We assume that $F$ is closed and convex valued. A simple computation shows that conditions of Theorem 3.1 are satisfied. Hence, the problem (5.1) has at least one random solution defined on $[0,1]$. Also, the hypothesis $\left(\mathrm{H}_{3}\right)$ is satisfied with

$$
\begin{gathered}
\Phi(t, w)=\frac{e^{3}}{1+w^{2}}, \text { and } \lambda_{\Phi}=\sum_{n=1}^{\infty} \frac{e^{-10 n}}{\Gamma(1+n \alpha)} . \\
\Phi(t, w)=\frac{e^{3}}{1+w^{2}}, \text { and } \lambda_{\Phi}=\frac{1}{\Gamma(1+\alpha)} .
\end{gathered}
$$

Indeed, for each $t \in[0,1]$, and $w \in \Omega$, we get

$$
\begin{aligned}
\left(I_{0}^{\alpha} \Phi\right)(t, w) & \leq \frac{e^{3}}{\left(1+w^{2}\right)} \sum_{n=1}^{\infty} \frac{e^{-10 n}}{\Gamma(1+n \alpha)} . \\
& =\lambda_{\Phi} \Phi(t, w) .
\end{aligned}
$$

Consequently, Theorem 3.2 implies that the problem (5.1) is generalized Ulam-Hyers-Rassias stable.

Example 2. Consider Hilfer fractional differential inclusion of the form

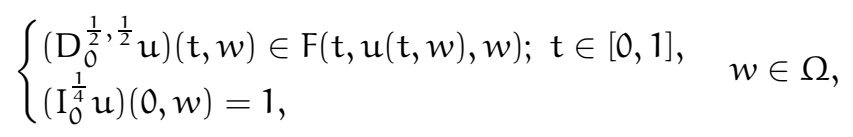

where

$$
\mathrm{F}(\mathrm{t}, \mathrm{u}(\mathrm{t}, w), w)=\frac{\mathrm{t}^{2}}{\left(1+w^{2}+|\mathrm{u}|\right) e^{10+\mathrm{t}}}[\mathrm{u}-1, \mathrm{u}] ; \mathrm{t} \in[0,1], w \in \Omega .
$$

Set $\alpha=\beta=\frac{1}{2}$, then $\gamma=\frac{3}{4}$. We assume that $F$ is closed valued. A simple computation shows that conditions of Theorem 3.3 are satisfied. Hence, the problem (5.2) has at least one random solution defined on $[0,1]$. Also, Theorem 3.4 implies that the problem (5.2) is generalized UlamHyers-Rassias stable.

\section{References}

[1] S. Abbas, W. A. Albarakati, M. Benchohra and J. Henderson, Existence and Ulam stabilities for Hadamard fractional integral equations with random effects, Electron. J. Differential Equations 2016 (2016), No. 25, pp 1-12. 
[2] S. Abbas, W. Albarakati, M. Benchohra and G. M. N'Guérékata, Existence and Ulam stabilities for Hadamard fractional integral equations in Fréchet spaces, J. Frac. Calc. Appl. 7 (2) (2016), 1-12.

[3] S. Abbas, W.A. Albarakati, M. Benchohra and S. Sivasundaram, Dynamics and stability of Fredholm type fractional order Hadamard integral equations, J. Nonlinear Stud. 22 (4) (2015), 673-686.

[4] S. Abbas and M. Benchohra, Uniqueness and Ulam stabilities results for partial fractional differential equations with not instantaneous impulses, Appl. Math. Comput. 257 (2015), 190-198.

[5] S. Abbas and M. Benchohra, Existence and Ulam stability for impulsive discontinuous fractional differential inclusions in Banach Algebras, Mediter. J. Math. 12 (4), (2015), 1245-1264.

[6] S. Abbas and M. Benchohra, Existence and Ulam stability results for quadratic integral equations, Libertas Math., 35 (2)(2015), 83-93.

[7] S. Abbas, M. Benchohra and G. M. N'Guérékata, Topics in Fractional Differential Equations, Springer, New York, 2012.

[8] S. Abbas, M. Benchohra and G. M. N'Guérékata, Advanced Fractional Differential and Integral Equations, Nova Science Publishers, New York, 2015.

[9] S. Abbas, M. Benchohra and A. Petrusel, Ulam stabilities for the Darboux problem for partial fractional differential inclusions via Picard Operators, Electron. J. Qual. Theory Differ. Equ., 1 (2014), 1-13.

[10] S. Abbas, M. Benchohra and S. Sivasundaram, Ulam stability for partial fractional differential inclusions with multiple delay and impulses via Picard operators, J. Nonlinear Stud. 20 (4) (2013), 623-641.

[11] M. Benchohra, J. Henderson, S. K. Ntouyas and A. Ouahab, Existence results for functional differential equations of fractional order, J. Math. Anal. Appl. 338 (2008), 1340-1350.

[12] A.T. Bharucha-Reid, Random Integral Equations, Academic Press, New York, 1972.

[13] C. Castaing and M. Valadier, Convex Analysis and Measurable Multifunctions, Lecture Notes in Mathematics 580, Springer-Verlag, Berlin-Heidelberg-New York, 1977.

[14] B. C. Dhage, Multi-valued condensing random operators and functional random integral inclusions, Opuscula Math., 31(1) (2011), 27-48.

[15] K. M. Furati and M. D. Kassim. Non-existence of global solutions for a differential equation involving Hilfer fractional derivative, Electron. J. Differential Equations 2013, No. 235, 10 pp. 
[16] K. M. Furati, M. D. Kassim, and N. e-. Tatar, Existence and uniqueness for a problem involving Hilfer fractional derivative. Comput. Math. Appl. 64 (2012), 1616-1626.

[17] A. Granas and J. Dugundji, Fixed Point Theory, Springer-Verlag, New York, 2003.

[18] J. Hadamard, Essai sur l'étude des fonctions données par leur développment de Taylor, $J$. Pure Appl. Math. 4 (8) (1892), 101-186.

[19] R. Hilfer, Applications of Fractional Calculus in Physics, World Scientific, Singapore, 2000.

[20] R. Hilfer. Threefold introduction to fractional derivatives, Anomalous transport: Foundations and applications, 17-73, 2008.

[21] D.H. Hyers, On the stability of the linear functional equation, Proc. Nat. Acad. Sci. 27 (1941), $222-224$.

[22] S.-M. Jung, Hyers-Ulam-Rassias Stability of Functional Equations in Mathematical Analysis, Hadronic Press, Palm Harbor, 2001.

[23] S.-M. Jung, Hyers-Ulam-Rassias Stability of Functional Equations in Nonlinear Analysis, Springer, New York, 2011.

[24] R. Kamocki and C. Obczńnski, On fractional Cauchy-type problems containing Hilfer's derivative, Electron. J. Qual. Theory Differ. Equ., 2016, No. 50, 1-12.

[25] A. A. Kilbas, Hadamard-type fractional calculus, J. Korean Math. Soc. 38 (6) (2001) 11911204.

[26] A. A. Kilbas, H. M. Srivastava and J. J. Trujillo, Theory and Applications of Fractional Differential Equations, Elsevier Science B.V., Amsterdam, 2006.

[27] G.S. Ladde and V. Lakshmikantham, Random Differential Inequalities, Academic Press, New York, 1980.

[28] A. Nowak, Applications of random fixed point theorem in the theory of generalized random differential equations, Bull. Polish. Acad. Sci. 34 (1986), 487-494.

[29] T.P. Petru, A. Petrusel. J.-C. Yao, Ulam-Hyers stability for operatorial equations and inclusions via nonself operators, Taiwanese J. Math. 15 (2011), 2169-2193.

[30] M. D. Qassim, K. M. Furati, and N.-e. Tatar, On a differential equation involving HilferHadamard fractional derivative, Abstract Appl. Anal., vol. 2012, Article ID 391062, 17 pages, 2012 .

[31] M. D. Qassim and N.-e. Tatar, Well-posedness and stability for a differential problem with Hilfer-Hadamard fractional derivative, Abstract Appl. Anal. Volume 2013, Article ID 605029, 12 pages, 2013. 
[32] Th.M. Rassias, On the stability of linear mappings in Banach spaces, Proc. Amer. Math. Soc. 72 (1978), 297-300.

[33] I. A. Rus, Ulam stability of ordinary differential equations, Studia Univ. Babes-Bolyai, Math. LIV (4)(2009), 125-133.

[34] I. A. Rus, Remarks on Ulam stability of the operatorial equations, Fixed Point Theory 10 (2009), 305-320.

[35] V. E. Tarasov, Fractional Dynamics: Application of Fractional Calculus to Dynamics of Particles, Fields and Media, Springer, Heidelberg; Higher Education Press, Beijing, 2010.

[36] Ž. Tomovski, R. Hilfer and H.M. Srivastava, Fractional and operational calculus with generalized fractional derivative operators and Mittag-Leffler type functions, Integral Transforms and Special Functions, 21 (11) (2010)797-814.

[37] C.P. Tsokos and W.J. Padgett, Random Integral Equations with Applications to Life Sciences and Engineering, Academic Press, New York, 1974.

[38] S.M. Ulam, A Collection of Mathematical Problems, Interscience Publishers, New York, 1968.

[39] J.-R. Wang, and Y. Zhang, Nonlocal initial value problems for differential equations with Hilfer fractional derivative. Appl. Math. Comput. 266 (2015), 850-859.

[40] H.Ye, J. Gao and Y. Ding, A generalized Gronwall inequality and its application to a fractional differential equation, J. Math. Anal. Appl. 328 (2007), 1075-1081.

[41] Y. Zhou, Basic Theory of Fractional Differential Equations, World Scientific, Singapore, 2014.

[42] Y. Zhou, Fractional Evolution Equations and Inclusions : Analysis and Control, Elsevier Science, 2016. 